\title{
Supracardiac total anomalous pulmonary venous connection in an adult woman
}

\section{Drenaje anómalo total de venas pulmonares variante supracardiaca en una mujer adulta}

\author{
Javier López ${ }^{1 *}$, Irene Torres¹, Jennifer Pacheco², Richard Quizhpe³, and Juan Flores ${ }^{1}$ \\ ${ }^{1}$ Cardiothoracic Surgery Department; ${ }^{2}$ Hemodynamics Department; ${ }^{3}$ Cardiology Department. Hospital de Especialidades José Carrasco Arteaga, \\ Cuenca, Azuay, Ecuador
}

Total anomalous pulmonary venous connection (TAPVC) is a congenital heart disease in which pulmonary venous circulation drains into the systemic venous system 1 . The existence of an atrial septal defect is essential for survival ${ }^{2}$. According to the modified Darling's classification, it can be supradiaphragmatic, infradiaphragmatic or mixed, with the former being divided into supracardiac, cardiac and infracardiac ${ }^{3}$.

Its global incidence is $2 / 100,000$ births $^{4}$, and it accounts for $1-3 \%$ of all congenital heart diseases ${ }^{1}$; the most common is supracardiac ${ }^{4}$. It is generated during intrauterine development and is caused by functional persistence of the primitive venous system ${ }^{5}$.

Diagnosis is carried out by echocardiography. Computed tomography (CT) or catheterization are useful if there are doubts or coexistence of associated anomalies $^{2}$. Since definitive diagnosis is obtained, there is already an indication for surgical correction. Natural evolution in biventricular hearts without surgical repair indicates a mortality of $80 \%$ within the first year of life ${ }^{1}$.

The main causes of hospital death are acute pulmonary edema and pulmonary hypertensive crisis. As complications, arrhythmias, low cardiac output and residual pulmonary vein obstruction are also reported' Risk factors include the infracardiac variant, presence of obstruction, preoperative critical condition, pulmonary veins hypoplasia and presence of another coexisting major congenital malformation ${ }^{1}$.
We present the case of a 36-year-old female patient who had two pregnancies with uncomplicated eutocic deliveries, after which she had chest pain and dyspnea on high exertion, which had progressed to dyspnea on small exertion at the time of admission, with cyanosis being added. Holosystolic murmur was detected on pulmonary and tricuspid areas on heart auscultation. The snowman sign was observed on chest X-ray and electrocardiogram showed a right bundle branch block pattern.

Imaging tests revealed significant dilatation of the right chambers, left ventricular ejection fraction of $75 \%$, moderate tricuspid regurgitation, atrial septal defect and supracardiac-variant TAPVC. A catheterization performed prior to admission reported moderate pulmonary hypertension (pulmonary artery systolic pressure [PASP]: $45 \mathrm{mmHg}$ ).

Total surgical correction was performed by posterior approach with a cardiopulmonary bypass time of 1 hour and 48 minutes, and a clamping time of 1 hour and 30 minutes. When longitudinal median sternotomy was performed, the innominate and vertical veins were observed to be significantly dilated (previous imaging tests indicated confluence of the four pulmonary veins towards a retropericardial collector draining into the innmominated vein through a vertical vein) (Fig.1). A longitudinal incision was made on the pericardium to surround the vertical vein with a silk ligature and

\section{Correspondence:}

*Javier López

E-mail: javieelopezz@gmail.com
Date of reception: 04-03-2020

Date of acceptance: 02-07-2020

DOI: 10.24875/ACME.M21000208
Available online: 19-07-2021

Arch Cardiol Mex (Eng). 2021;91(2):232-234 www.archivoscardiologia.com 2604-7063 / @ 2020 Instituto Nacional de Cardiología Ignacio Chávez. Published by Permanyer. This is an open access article under the CC BY-NC-ND license (http://creativecommons.org/licenses/by-nc-nd/4.0/). 
completely dissect the posterior collector. Once cardiopulmonary bypass was initiated, the vertical vein was ligated. On electromechanical arrest and a temperature of $28{ }^{\circ} \mathrm{C}$, the collector and left atrium were transversely incised on the posterior wall up to the left atrial appendage, with a side-to-side anastomosis being performed between these two structures without causing tissue tension and avoiding residual stenosis on the anastomosis (Fig. 2). This approach was chosen because it is safe, offers effective exposure and does not increase the incidence of atrial arrhythmias because it does not require further atrial incisions ${ }^{6}$. By means of right atriotomy, atrial septal defect closure was carried out with a fenestrated bovine pericardium patch.

The patient remained 3 days in the intensive care unit, where she was extubated on her first day and remained with inotropic support with milrinone and norepinephrine for 24 hours. Subsequently, she had a good evolution, with a control echocardiogram reporting PASP of $59 \mathrm{mmHg}$, intact septa, and at left atrial posterior level, venous drainage collector single flow. She was discharged 11 days after the procedure.

Pregnancy is a state of high hemodynamic demand. Cardiac output rises up to $100 \%$ during the third trimester $^{5}$, and it is therefore common for pregnant women to develop symptoms associated with otherwise silent congenital malformations. Pregnancy-associated TAPVC is rare and is even considered an indication for pregnancy termination 7 . The fact that this patient had undergone two pregnancies and eutocic deliveries during which she remained asymptomatic and undiagnosed stands out.

This unusually late evolution is attributable to the lucky presence of some known protective factors, such as the defect being of the supracardiac variant, $a b$ sence of other concomitant malformations that complicate this condition, a wide atrial septal defect that allowed unrestricted passage of blood, coupled with tricuspid regurgitation, which in turn increased this flow towards the left atrium, and absence of venous obstruction on the trajectory towards the right atrium ${ }^{5}$.

Once the diagnosis is established, a thorough anatomical and clinical assessment of each case should be carried out in order to define the behavior to be followed. Pulmonary pressures right catheterization becomes relevant, since pulmonary hypertension late stages can thereby be detected, which is a highly common complication because it is part of natural evolution of the disease, which might even contraindicate surgical resolution ${ }^{8}$. The imaging tests of our patient were carried out over several months, since she resides in another province and access was complicated for her.

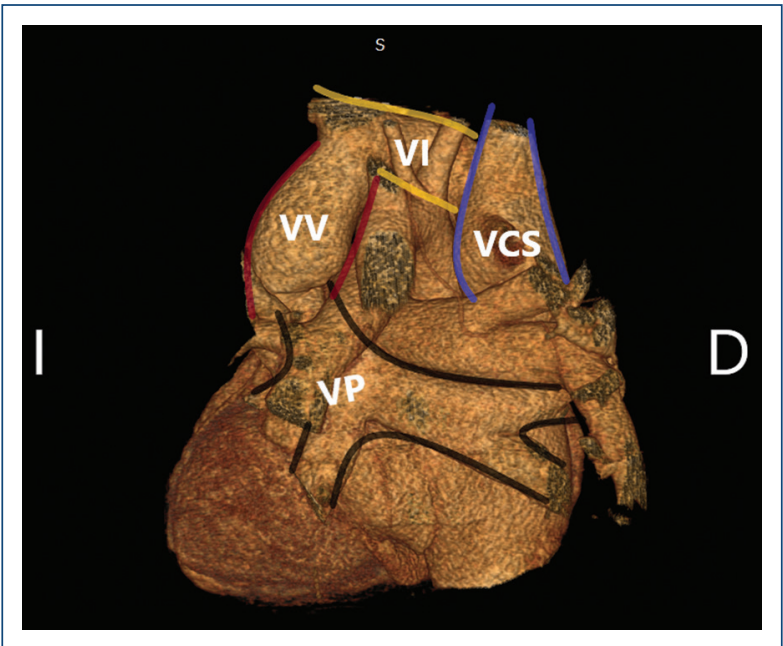

Figure 1. Computed tomography angiogram, threedimensional reconstruction. Posterior view. Supracardiac pulmonary veins (VP) total anomalous connection is observed, with a collector that drains into a vertical vein (VV), which in turn drains into the innominate vein (VI) and into superior vena cava (VCS).

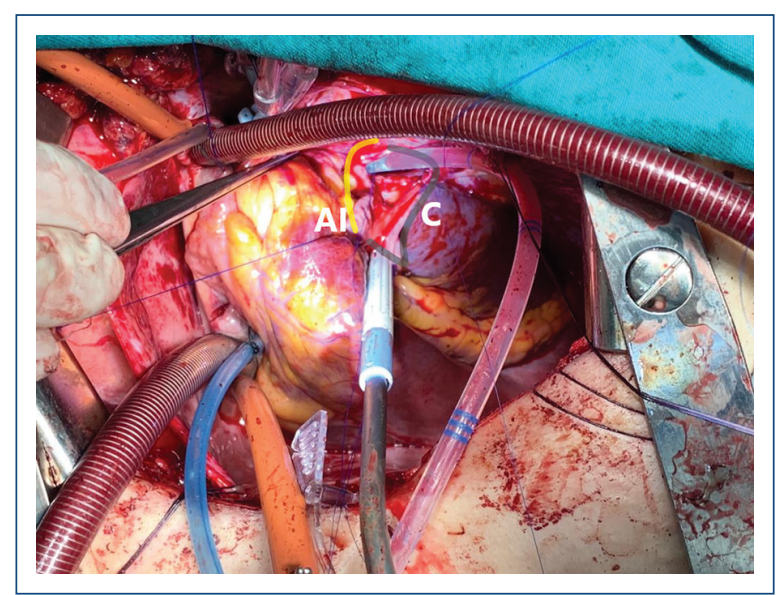

Figure 2. Collector-to-left atrium anastomosis. On cardiopulmonary bypass pump with arrested heart and clamped aorta, using a posterior approach with dislocation of the heart towards the surgeon, anastomosis between the collector (C) and left atrium (Al) posterior wall is performed.

The initially-performed catheterization showed moderate pulmonary hypertension, which is why it was decided that surgical resolution was still plausible.

This procedure is rare in adults, and its perioperative morbidity has therefore not been well studied in this type of patients. There are case series with small groups reporting good survival ${ }^{6}$, referring complications 
such as respiratory distress, pulmonary hypertensive crisis and low cardiac output, favored by preexisting pulmonary hyperflow. Moreover, as a major structural complication, pulmonary veins-to-left atrium anastomosis residual stenosis should especially be taken into account, since it can occur in up to $19 \%$ of cases ${ }^{9}$.

Since the beginning, placing a fenestrated patch was decided in order to prevent post-surgical complications associated with severe pulmonary hypertension, given that despite showing moderate pulmonary hypertension on initial catheterization, during previous month she had experienced functional class deterioration with cyanosis added to her symptomatology; these are clinical manifestations that indicate increased pulmonary hypertension. In addition, there may be pulmonary pressure variations secondary to the altitude; there are reported cases where residents of high altitudes may have significant increases in pulmonary pressure when moving to another locality ${ }^{10}$.

Patient evolution was excellent; postsurgical control echocardiogram showed an interatrial septum without residual flows or severe pulmonary hypertension and adequate flow at the pulmonary veins anastomosis level without stenosis.

This case is relevant because it involves a patient with a peculiar evolution of a TAPVC. Of note, although pulmonary arterial pressure of high altitude residents is known to be higher, our patient did not develop severe pulmonary hypertension despite living in a city located 2,500 meters above sea level. Similarly strange is her adult-life history with several gestations during which she remained completely asymptomatic despite the increased hemodynamic demand this situation entails.

Due to the risk of complications with right heart failure and pulmonary hypertension, using a fenestrated patch for atrial septal defect closure was decided. The procedure was carried out by posterior approach with adequate visualization of structures. This is the first case of TAPVC total correction in Ecuador.

Our patient had an excellent evolution, with adequate hemodynamic function and significant symptomatology improvement, and thus she has a good long-term prognosis.

\section{Funding}

None.

\section{Conflicts of interest}

The authors declare that they have no conflicts of interest.

\section{Ethical disclosures}

Protection of human and animal subjects. The authors declare that no experiments have been performed on humans or animals for this research.

Confidentiality of data. The authors declare that they have followed the protocols of their work center on the publication of patient data.

Right to privacy and informed consent. The authors have obtained informed consent from the patients and/or subjects referred to in the article. This document is in the possession of the corresponding author.

\section{References}

1. Rivera Ladino KM, Naranjo Ugalde AM, Selman-Housein Sosa E, Frias F. Drenaje anómalo total de venas pulmonares, veinticuatro años de tratamiento quirúrgico. Cardiocentro William Soler. Rev Cubana Cardiol Cir Cardiova. 2013;19:21-4.

2. Aroca A, Polo L, Bret M, López-Ortego P, González A, Villagrá F. Drenaje venoso pulmonar anómalo total. Técnicas y resultados. Cir Cardiov. 2014:21:90-6.

3. Muñoz Castellanos L, Kuri Nivon M, Sánchez CA. Estudio morfopatológico de la conexión anómala total de venas pulmonares. Rev Arch Cardiol México. 2007;77:265-74.

4. Farfán E, Echeverría M, Salgado G, Navarro S, Inostroza A, Inzunza O. Conexión venosa pulmonar anómala. Reporte de un caso. Int J Morphol. 2018;36:1197-201.

5. Talib N, Sayuti K, Abdullah MS, Mohd Zain MR. Beating the odds: a rare case of supracardiac total anomalous pulmonary venous return (TAPVR) in an adult patient. BMJ Case Rep. 2018;2018:bcr2017221074.

6. Talwar S, Choudhary SK, Reddy S, Saxena A, Kothari SS, Juneja R, et al. Total anomalous pulmonary venous drainage beyond childhood. Interact Cardiovasc Thorac Surg. 2008;7:1058-61.

7. Bangal VB, Kanika G, Gavhane SP, Gangapurwala S. Rare case of pregnancy with total anomalous pulmonary venous connection (TAPVC). Int J Biomed Res. 2014;5:143-4.

8. Atik FA, Jaramillo M, Afiune JY, Caneo LF. Complete repair of total anomalous pulmonary venous connection in adult patient. Braz $\mathrm{J}$ Cardiovasc Surg. 2009;24:81-3.

9. Wu FM, Emani SM, Landzberg MJ, Valente AM. Rare case of undiagnosed supracardiac total anomalous pulmonary venous return in an adult. Circulation. 2014;130:1205-7.

10. Spielvogel H. Presión arterial pulmonar y altura. Cuad Hosp Clínicas. 2007;52:86-92. 